\title{
Impact of gastroesophageal reflux in the pathogenesis of tracheal stenosis
}

\author{
Paulo Francisco Guerreiro Cardoso, Helio Minamoto, Benoit Jacques Bibas, Paulo Manuel Pego-Fernandes \\ Divisao de Cirurgia Toracica, Instituto do Coracao, Hospital Das Clinicas HCFMUSP, Faculdade de Medicina, Universidade de Sao Paulo, Sao \\ Paulo, SP, Brazil \\ Contributions: (I) Conception and design: PF Cardoso, H Minamoto; (II) Administrative support: PM Pego-Fernandes; (III) Provision of study \\ materials or patients: PF Cardoso, H Minamoto, PM Pego-Fernandes; (IV) Collection and assembly of data: PF Cardoso, H Minamoto; (V) Data \\ analysis and interpretation: PF Cardoso, H Minamoto, BJ Bibas; (VI) Manuscript writing: All authors; (VII) Final approval of manuscript: All \\ authors. \\ Correspondence to: Paulo Francisco Guerreiro Cardoso. Divisao de Cirurgia Toracica, Instituto do Coracao, Hospital Das Clinicas HCFMUSP, \\ Faculdade de Medicina, Universidade de Sao Paulo, Rua Dr. Eneas de Carvalho Aguiar 44, bloco II, 7 andar, Sao Paulo, SP 05403-904, Brazil. \\ Email: cardosop@gmail.com.
}

\begin{abstract}
Benign airway stenosis is a multifactorial and heterogeneous disease often occurring after tracheal intubation. Despite the frequent finding of pathological gastroesophageal reflux (GER) in benign tracheal stenosis, the cause-and-effect relationship between these two entities and its impact on the outcome of the stenosis itself have not been established. The altered ventilatory dynamics caused by an increased thoracoabdominal pressure gradient in such patients has been proposed as a central cause. The presence of GER in a setting of microaspiration can also induce changes in the local collagen proliferation response, as well as in the local microbiome of the tracheal stenosis site, which may potentially cause and enhance the harm imposed to the already diseased tracheal wall. Diagnosis of GER remains underestimated in the general population, thus making its accurate detection and treatment in central airway stenosis a matter of investigation. The high prevalence of GER in tracheal stenosis patients often occurs in the absence of typical upper digestive signs and symptoms, therefore requiring an objective assessment using a 24-hour ambulatory esophageal $\mathrm{pH} /$ impedance study that has shown abnormal results in more than half the patients. The impact of the treatment of GER in patients with benign tracheal has been scarcely reported. Our group showed recently that the surgical control of GER through laparoscopic fundoplication in selected patients with tracheal stenosis can improve substantially the chance of resolution of the tracheal stenosis as opposed to the medical management with high dose proton pump inhibitors. This chapter describes the impact of GER in the pathogenesis of tracheal stenosis with a focus on its mechanisms, diagnosis and treatment strategy.
\end{abstract}

Keywords: Tracheal stenosis; gastroesophageal reflux (GER); treatment; outcomes

Submitted Dec 24, 2019. Accepted for publication Feb 25, 2020.

doi: $10.21037 /$ tcr.2020.03.24

View this article at: http://dx.doi.org/10.21037/tcr.2020.03.24

\section{Introduction}

Benign airway stenosis is a multifactorial and heterogeneous disease often deriving from prolonged tracheal intubation. The reported incidence of tracheal stenosis following tracheostomy and laryngotracheal intubation varies from $0.6 \%$ to $21 \%(1-4)$. The local factors contributing for the occurrence of airway stenosis include local airway trauma produced by the contact between the tracheal wall and the endotracheal tube, inefficient management of the cuff pressures, technical inadequacies of tracheostomy, local endoluminal bacterial proliferation. Systemic factors such as unstable cardiovascular disease, presence of metabolic diseases and infections also contribute to the tracheal wall 
injury and subsequently to stenosis. Other less common causes are penetrating tracheal trauma, autoimmune diseases (e.g., Wegener's granulomatosis, relapsing polychondritis, sarcoidosis, amyloidosis), congenital, primary, secondary neoplastic diseases, and idiopathic $(2,5)$.

Gastroesophageal reflux (GER) has been associated to laryngeal and pulmonary diseases $(6,7)$. The participation of GER in benign tracheal stenosis has also been described, although the cause-and-effect relationship is not always clearly established. Furthermore, the diagnosis of GER itself is underestimated in the general population. A national inquiry enrolling 14,000 adult subjects found a prevalence of heartburn once a week of $11.9 \%$ in the Brazilian urban population (8), and $19.8 \%$ in the American population (9). Given the prevalence of GER in the general population and considering the possibility of the development or the aggravation of the airway stenosis in patients with GER, it became increasingly important to consider GER as an adjuvant factor in selected patients with central airway stenosis (10). However, the character of GER in these patients does not always follow the well-known clinical features of GER disease (GERD). Therefore, the accurate diagnosis of GER and its effective treatment in patients with central airway stenosis requires objective investigation.

This chapter is focused on the role of GER in airway stenosis, with emphasis on the pathophysiology, clinical and diagnostic features as well as the potential impact of GER both in the treatment strategy and in the outcome of benign airway stenosis.

\section{Correlation between GER and upper airway stenosis}

The coexistence of GER and respiratory disease has been subclassified into the extraesophageal syndromes $(6,11)$. As opposed to the correlation between GER and distal airway and lung diseases, such as asthma $(12,13)$, pulmonary fibrosis (14), bronchiolitis obliterans (15-17) and airway hyperresponsiveness (18), there are few studies on upper airway diseases. The majority are concentrated on laryngeal disorders, such as laryngospasm, contact granulomas and vocal cord dysfunction (19-21), and few are focused on central airway stenosis. The idiopathic subglottic stenosis is an exception where the association with GER has been described initially by Brandenburg in 1972 (22) who was the first to point out to laryngopharyngeal reflux as an adjuvant in the development of subglottic stenosis, and ever since there have been frequent reports of this association (23).
Bain et al. (24) described the first case of successful improvement of laryngotracheal stenosis after surgical treatment for GERD. Little et al. (25), reported a case of a 12 -year-old girl with no improvement of post-intubation subglottic stenosis despite several previous treatment strategies including an open airway repair with cartilage interposition where severe reflux to the proximal airway was observed. This observation led them to start treatment with $\mathrm{H} 2$ blockers that ultimately yielded to the resolution of the stenosis. The case led the same authors to the design of a canine model of subglottic stenosis to examine whether or not the gastric acid was a contributing factor to the development of subglottic stenosis after the production of a mucosal lesion. In control animals, the mucosal lesions produced in the trachea healed without the development of stenosis. On the other hand, the animals where the mucosal lesion was exposed to gastric acid developed subglottic stenosis.

Koufman et al. in 1991 (20) published a seminal clinical study where $78 \%$ of the patients with tracheal and subglottic stenosis had GER as verified by an abnormal 24hour esophageal. Such a high prevalence of abnormal acid reflux occurred in the absence of typical upper digestive symptoms. Toohill et al. in 1998 (26) also described a higher incidence of pharyngeal acid reflux events in the 24-hour esophageal $\mathrm{pH}$ monitoring of laryngotracheal stenosis patients. The treatment of GER in this series led to an improvement in the treatment results. A case-control study found that $59 \%$ of the biopsies of subglottic stenosis tested positive in a pepsin essay (27). Unfortunately, the widespread use of the pepsin essay remains limited because the cutoff values have not been established yet (28).

Laryngotracheal stenosis has been associated with an abnormal 24-hour esophageal $\mathrm{pH}$ study in more than half the patients (29), whereas laryngeal acid exposure is present in up to $86 \%(30)$.

Recent studies on benign tracheal stenosis described the presence of GERD in $42 \%$ to $69 \%(10,31,32)$. Therefore, the correlation between GER and upper airway stenosis is probably not just coincidental. The next question is whether GER plays a role in the outcome of tracheal stenosis. In this context, GER has a different character when compared to the usual findings in GERD. The very concept of GERD encompasses well-defined criteria that includes the presence of typical reflux symptoms and the endoscopic finding of esophagitis. Conversely, the patients with extraesophageal syndromes such as airway stenosis often lack the presence of typical reflux symptoms as well as endoscopic abnormalities 
in the esophagus. Therefore, it requires an objective investigation of GER utilizing esophageal function tests to accurately diagnose and characterize reflux.

In a cohort of 175 patients with benign tracheal stenosis studied at our center, only $21 \%$ presented with typical reflux symptoms (heartburn and acid regurgitation), $42 \%$ had an abnormal ambulatory esophageal $\mathrm{pH}$ study, and endoscopic abnormalities associated with reflux were found in $18.5 \%$ of the patients (31). The reflux pattern showed a predominance of supine and laryngopharyngeal reflux, which parallels the GER pattern we described previously in other respiratory diseases such as pulmonary fibrosis (14), asthma (12,13), and also in lung transplant candidates (16). Decannulation failure has also been related to the presence of GERD. Tawfik et al. (33) showed in a cohort of 95 patients submitted to laryngotracheal reconstruction that the factors associated with decannulation failure 1 year after surgery were GERD, Cotton-Myer grade 4 stenosis and diabetes.

\section{Pathophysiology of tracheal stenosis in patients with GER}

The cause and effect relationship between central airway obstruction and GER has been mostly based on descriptions of clinical reports and in small clinical series.

\section{Ventilatory dynamics}

A plausible explanation for the finding of GER in tracheal stenosis patients is the altered ventilatory dynamics caused by an increased thoracoabdominal pressure gradient. The available clinical data on the effects of laryngotracheal stenosis on upper airway aerodynamics showed an increased resistance and a decreased airflow that are not compensated by mouth breathing (34). The increase in airflow velocity in the stenotic area is associated with higher resistance to airflow creating a turbulent flow and resulting dyspnea.

\section{The thoracoabdominal pressure gradient}

The mechanism involving variation in thoracoabdominal and transpulmonary pressures reflected in the airway dynamics includes altered flow in tracheal stenosis. The increased thoracoabdominal pressure gradient acts as a facilitator of GER in this scenario. A recent clinical study focused on the effects of laryngotracheal stenosis on upper airway aerodynamics demonstrated both an increased resistance and a decreased airflow not compensated by oral breathing (34). Experimentally, such mechanism was tested in rats and dogs creating a thoracoabdominal pressure gradient by means of partial central airway obstruction caused by placing progressively narrower tracheostomy cannulas. These studies showed that GER was produced by overcoming of the gastroesophageal antireflux barrier $(35,36)$.

Another experimental study carried out in a canine model used telemetry for the measurement of the intrapleural and intrabdominal pressure in order to obtain transdiaphragmatic pressures, along with 24-hour intraesophageal $\mathrm{pH}$ recordings to obtain a reflux index in dogs submitted to banding of the intrathoracic trachea above the carina to reduce more than $50 \%$ of the tracheal diameter. The results in this complex model failed to demonstrate the presence of GER as shown by the $\mathrm{pH}$ recordings and reflux index after the creation of the thoracoabdominal pressure gradient. The major limitations were the number of animals and the method for producing of tracheal obstruction (37).

The role of the thoracoabdominal pressure gradient in patients with end-stage lung disease provides an interesting analogy to the mechanism causing GER found in central airway obstruction. Masuda et al. (38) measured the thoracoabdominal pressure gradient (intra-abdominal pressure minus intrathoracic pressure during inspiration) using esophageal manometry in lung transplant candidates with end-stage pulmonary disease. The adjusted thoracoabdominal pressure gradient was also calculated (thoracoabdominal pressure gradient minus the resting lower esophageal sphincter pressure). They found that patients with restrictive lung disease had a higher thoracoabdominal pressure gradient and higher incidence of pathologic GER on the 24-hour pH study compared to patients with obstructive lung disease.

Despite the existing clinical and experimental evidence on the role of thoracoabdominal pressure gradient in GER, the question that remains unanswered is whether such mechanism can also be applied to patients wearing a tracheostomy. Since the cannula bypasses both the stenosis and the glottis, it reduces the local resistance to airflow during spontaneous breathing and might not affect the thoracoabdominal pressure gradient.

\section{Inflammation and tissue remodeling}

The common denominator of the airway related problems in patients with GER is the inflammatory 
component associated with the presence of neutrophilic, neuroendocrine, inflammatory cells and cytokines causing airway inflammation and increased local oxidative stress (39).

The pathophysiology of benign tracheal stenosis has been extensively studied in subglottic stenosis which is considered as a local fibroproliferative disorder associated with the damage to the tracheal epithelium followed by edema and inflammation. This is followed by a local tissue remodeling as a result of the migration of fibroblasts into the injured site, local deposition of extracellular matrix and subsequent fibroproliferation that will ultimately result in the airway stenosis itself (40). Dillard et al. (41) produced subglottic injury in rats and found an expression of transforming growth factor-beta 1 (TGF-beta1), which is also involved in the pathogenesis of other fibrotic diseases. The TGF-beta1 was found into the submucosal fibrotic matrix below the injured airway epithelium. The elevations in fibronectin and procollagen were also described in this study.

Jarmuz et al. (42) designed an in vitro experiment based on this assumption that TGF-betal can stimulate the transformation of tracheal fibroblasts into myofibroblasts thus enabling the formation of increased production of matrix and scar. Rat tracheal fibroblasts exposed to TGFbeta1 or gastric juice increased the expression of alphasmooth muscle actin and contraction of collagen gels. These findings suggested the presence of other adjuvant factors in the gastric juice acting in tissue remodeling of the tracheal injury through the stimulation of the differentiation of fibroblasts into myofibroblasts.

Some components of the duodenal juice such as enzymes and bile acids are often found in the gastric refluxate in the lower and upper esophagus. The potential role of bile acids in acquired laryngotracheal stenosis was evaluated in vitro using the supernatant of cell cultures exposed to different bile acids (i.e., cholic, chenodeoxycholic, deoxycholic, and lithocholic) and greater concentration of TGF-beta 1 and matrix metalloproteinase-9 were measured. Lithocholic acid and deoxycholic acid induced a significantly higher expression of procollagen protein along with an upregulation of fibronectin and downregulation of E-cadherin observed with all bile acids tested, except for the deoxycholic acid. Therefore, in the event of a tracheal injured site being exposed to gastric and biliary refluxate, it increases the potential risk for the development of stenosis (43).

\section{The local microbiome}

The role of the local tracheal microbiome in the outcome of the stenosis is unclear. Recently, the role of microbiota as we know it has changed from being considered as a simple eventual colonization from the environment to a constitutive component of the human organism. Acting as a genetic characterization of the entire microbiota in a specific tissue, the microbiome has the ability to dialogue with the immune system, thus regulating and modulating the immune response against the host both locally and systemically, potentially interfering in other organs and systems (44). An example is the association of periodontal bacteria with cardiovascular disease has been reported recently $(45,46)$. Another recent study in children showed that the tracheal microbiota differs in the presence or absence of concomitant respiratory infection, particularly in regards to the frequencies of Haemophilus, Pseudomonas, Corynebacterium and Acinetobacter, regardless of the season (47).

Theoretically, the changes in the tracheal endoluminal microbiome can also be triggered by the local milieu as a result of microaspiration of the gastric acid refluxate into the airway. In order for the refluxate to reach the proximal trachea, it has to pass through the pharynx and larynx where it is exposed to the oral microbiota. Other important variable is the presence of a tracheostomy or stenting of the stenosis either by a silicone or a covered metallic used to maintain airway patency. Furthermore, the tracheal appliances harbor a biofilm over its surface containing a microbiota that changes depending on the local conditions such as local humidity, temperature and $\mathrm{pH}$. The presence of certain metabolic and autoimmune diseases such as diabetes mellitus also have the ability to change the microbiota (Figure 1).

The constant exposure of the silicone stent to the aerodigestive secretions creates a local microbial challenge that may damage the already diseased tracheal wall at the stenosis site thus interfering in the resolution of the stenosis itself (48). The formation of granulation tissue at the ends of the stent and underneath its surface have been described as a result of both mechanical contact and the colonization by Staphylococcus aureus and Pseudomonas aeruginosa (49). The repeated local tissue aggression carries the potential to perpetuate the process which thereby increases both the extent and the severity of the stenosis. This may delay and impair the definitive treatment, either by surgical resection or decannulation (50). A preliminary study of the microbial contents of silicone T-tube stents using standard cultures in patients with benign tracheal stenosis, we found a predominance of bacteria, particularly Pseudomonas aeruginosa, followed by polymicrobial population and 

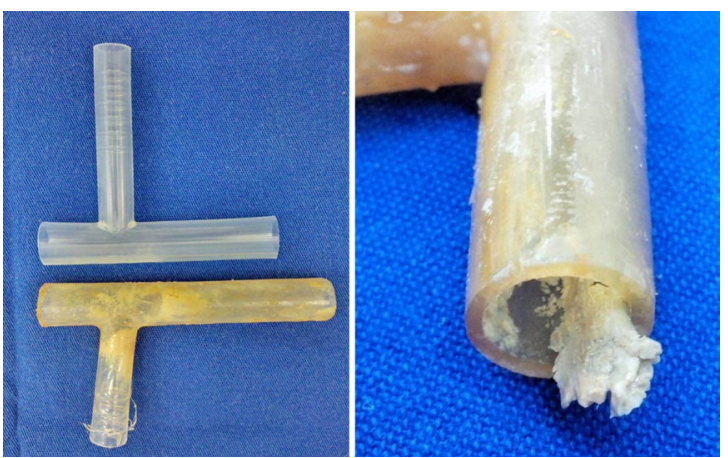

Figure 1 Biofilm in the silicone T-tube. Left: a new and clear silicone T-tube (above), compared with an used T-tube (below) removed from a patient after 6 months of use showing an extensive and adherent biofilm; right-proximal end of a T-tube removed from a patient with type 1 diabetes and subglottic stenosis showing extensive colonization of the biofilm by bacteria and fungi (Candida sp.).
Serratia marcescens, and fungi (Candida sp.) (unpublished data) (Figure 2).

Currently, the best way to study the microbiome is by mapping the microbiota directly from the stenosis site or from the silicone prosthesis through $16 \mathrm{~S}$ rRNA gene sequencing. The DNA of the biofilm samples is extracted, and the microbial diversity of the stent biofilm is determined by sequencing the V3-V4 region of the bacterial $16 \mathrm{~S}$ rRNA gene. The taxonomic classification is performed using the Human Oral Microbiome Database (HOMD) (http://www. homd.org). The microbial composition is analyzed for the indices of richness, alpha and beta-diversity and relative abundance at different taxonomic levels (51). We performed a microbiome analysis of the different parts of a tracheal silicone T-tube removed during change of the prosthesis in a patient without GERD. Samples were collected from 5 different regions and DNA was extracted (Figure 3).

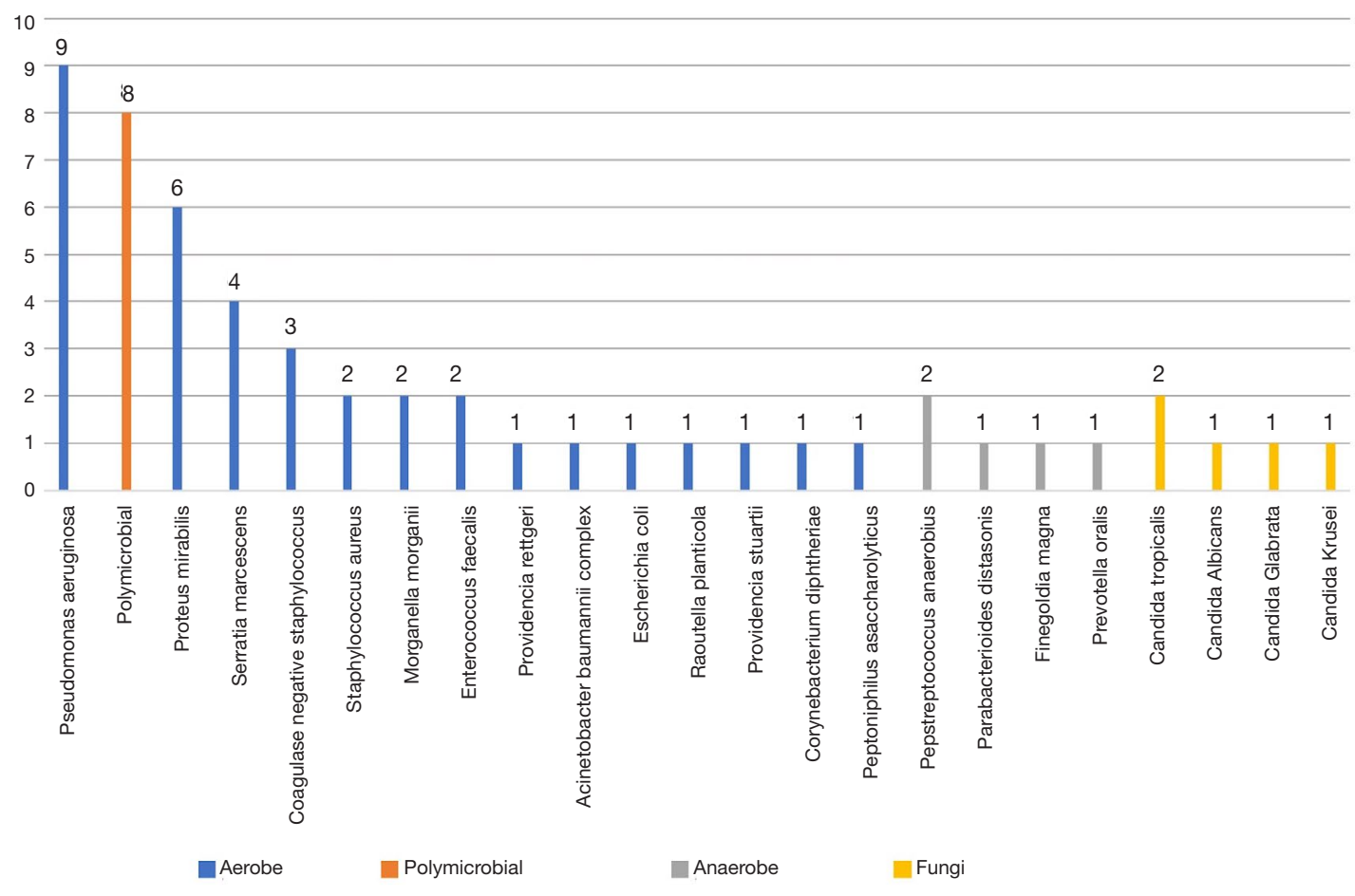

Figure 2 Frequency of the microbial contents of the distal extremity of silicone T-tube stents obtained in aerobe standard culture medium of the distal extremity of the stent $(\mathrm{n}=27)$ (Cardoso PF, Bibas BJ, and Minamoto H, unpublished data). 

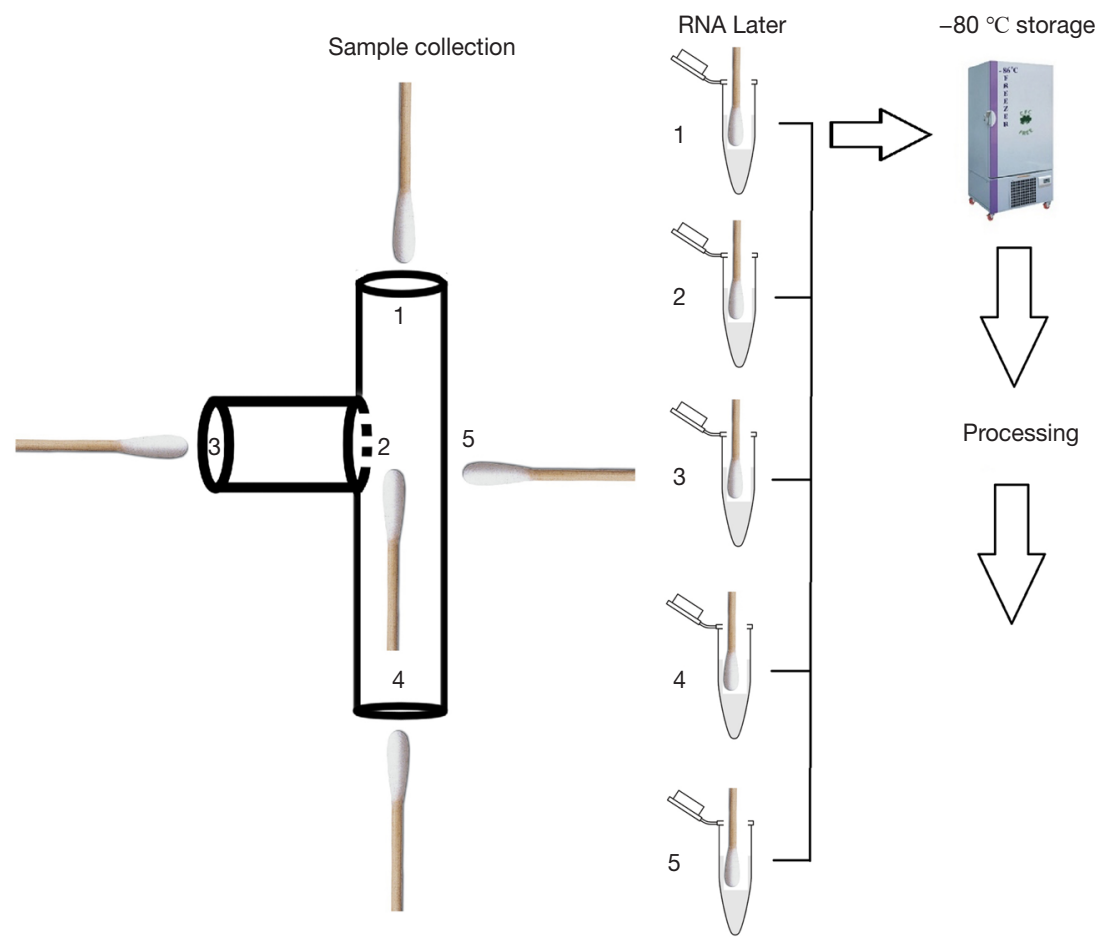

Figure 3 Five sample collection sites from the T-tube.

The frequency of the global microbiological findings is described in a taxonomy summary provided by the software after total DNA sequencing (Macrogen, Korea) (Figure 4).

A study is now underway at our institution to evaluate the differences in the microbiome of the silicone stents between tracheal stenosis patients with and without GER. The analysis of the microbiome of the saliva and the biofilm of these prostheses will provide data to the understanding of the outcome of tracheal stenosis in patients subjected to stenting. The comparison between patients with and without gastro-esophageal reflux disease will help us determine whether the acidification of the medium has an impact in the local microbiome. This will open the possibility of the future use of silicone surface modified stents using bacteriostatic nanocomposites, antibiotics and anti-proliferative drugs. The relationship between the microbiome of the oral cavity and the T-tube will also enable an investigation on the possibility of co-colonization of oral bacteria in the presence of fungi.

\section{Diagnosis of tracheal stenosis associated with GER}

The diagnosis of tracheal stenosis relies on the presence of airway narrowing to become clinically apparent. Dyspnea is the clinical hallmark of the disease, followed by other features such as stridor, wheezing, cough and exercise limitation. The presence of typical digestive symptoms, such as heartburn and acid regurgitation often associated with GER, is seldom found in tracheal stenosis and in laryngeal disorders (20). A study on tracheal stenosis found GERD in $47 \%$ of the patients, although only $18 \%$ of them actually had post-intubation stenosis (10). On the other hand, extraesophageal manifestations can be found in many patients with heartburn who lack laryngeal symptoms (52). In a cohort of 175 patients with tracheal stenosis studied at our center, the presence of typical GER symptoms (weekly combination of heartburn and acid regurgitation) was found in $21 \%$ of the whole cohort, and in $12.6 \%$ patients with tracheal stenosis with an abnormal 24-hour esophageal $\mathrm{pH}$ study. Nevertheless, patients with typical GER symptoms showed a higher chance of having an abnormal 24-hour esophageal $\mathrm{pH}$ study (31).

Unlike GERD, the lack of typical symptoms and the absence of esophagitis in the upper gastrointestinal endoscopy in patients with extraesophageal manifestations of GER makes the clinical diagnosis a lot more difficult to establish without objective 

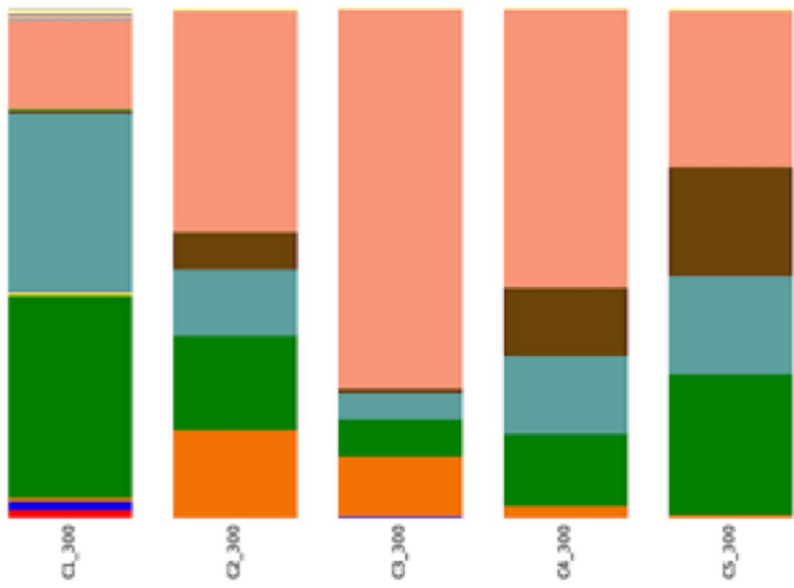

\begin{tabular}{|c|c|c|c|c|c|c|c|}
\hline & & Total & C1_300 & C2_300 & C3_300 & C4_300 & C5_300 \\
\hline \multirow[t]{20}{*}{ Legend } & Taxonomy & $\%$ & $\%$ & $\%$ & $\%$ & $\%$ & $\%$ \\
\hline & Unassigned;Other & $0.3 \%$ & $1.5 \%$ & $0.0 \%$ & $0.0 \%$ & $0.0 \%$ & $0.0 \%$ \\
\hline & k_Archaea;p_Euryarchaeota & $0.4 \%$ & $1.6 \%$ & $0.1 \%$ & $0.1 \%$ & $0.0 \%$ & $0.1 \%$ \\
\hline & k_Bacteria;p_Actinobacteria & $6.5 \%$ & $0.8 \%$ & $17.2 \%$ & $11.7 \%$ & $2.3 \%$ & $0.5 \%$ \\
\hline & k_Bacteria;p_Bacteroidetes & $21.5 \%$ & $39.6 \%$ & $18.5 \%$ & $7.4 \%$ & $14.2 \%$ & $27.7 \%$ \\
\hline & k_Bacteria;p_Chloroflexi & $0.0 \%$ & $0.0 \%$ & $0.0 \%$ & $0.0 \%$ & $0.0 \%$ & $0.0 \%$ \\
\hline & k_Bacteria;p_Cyanobacteria & $0.1 \%$ & $0.4 \%$ & $0.0 \%$ & $0.0 \%$ & $0.0 \%$ & $0.0 \%$ \\
\hline & k_Bacteria;p_Deferribacteres & $0.0 \%$ & $0.0 \%$ & $0.0 \%$ & $0.0 \%$ & $0.0 \%$ & $0.0 \%$ \\
\hline & k_Bacteria;p_Fibrobacteres & $0.0 \%$ & $0.1 \%$ & $0.0 \%$ & $0.0 \%$ & $0.0 \%$ & $0.0 \%$ \\
\hline & k_Bacteria;p_Firmicutes & $17.6 \%$ & $35.4 \%$ & $12.9 \%$ & $5.3 \%$ & $15.2 \%$ & $19.3 \%$ \\
\hline & k_Bacteria;p_Fusobacteria & $8.6 \%$ & $0.3 \%$ & $7.4 \%$ & $0.8 \%$ & $13.2 \%$ & $21.1 \%$ \\
\hline & k_Bacteria;p_Lentisphaerae & $0.0 \%$ & $0.1 \%$ & $0.0 \%$ & $0.0 \%$ & $0.0 \%$ & $0.0 \%$ \\
\hline & k_Bacteria;p_Planctomycetes & $0.0 \%$ & $0.2 \%$ & $0.0 \%$ & $0.0 \%$ & $0.0 \%$ & $0.0 \%$ \\
\hline & k_Bacteria;p_Proteobacteria & $44.1 \%$ & $17.4 \%$ & $43.3 \%$ & $74.3 \%$ & $54.7 \%$ & $30.8 \%$ \\
\hline & k_Bacteria;p_SR1 & $0.1 \%$ & $0.2 \%$ & $0.0 \%$ & $0.0 \%$ & $0.0 \%$ & $0.0 \%$ \\
\hline & k_Bacteria;p_Spirochaetes & $0.2 \%$ & $0.7 \%$ & $0.1 \%$ & $0.1 \%$ & $0.0 \%$ & $0.1 \%$ \\
\hline & k_Bacteria;p_Synergistetes & $0.0 \%$ & $0.0 \%$ & $0.0 \%$ & $0.0 \%$ & $0.0 \%$ & $0.0 \%$ \\
\hline & k_Bacteria;p_TM7 & $0.1 \%$ & $0.4 \%$ & $0.0 \%$ & $0.0 \%$ & $0.0 \%$ & $0.0 \%$ \\
\hline & k_Bacteria;p_Tenericutes & $0.5 \%$ & $0.7 \%$ & $0.5 \%$ & $0.2 \%$ & $0.3 \%$ & $0.5 \%$ \\
\hline & k Bacteria;p_Verrucomicrobia & $0.1 \%$ & $0.3 \%$ & $0.0 \%$ & $0.0 \%$ & $0.0 \%$ & $0.0 \%$ \\
\hline
\end{tabular}

Figure 4 Example of a taxonomy summary obtained from the analysis of region C1 (luminal surface of the upper limb of a silicone T-tube).

testing. In our cohort, the abnormality found in upper gastrointestinal endoscopy occurred in only $18.5 \%$ of the patients with tracheal stenosis (31). Therefore, the detection of GER using esophageal function testing provides a reliable and accurate assessment that enables detection and characterization of reflux. It can be carried out either by conventional stationary manometry and dual probe 24-hour esophageal $\mathrm{pH}$ testing, or highresolution manometry and esophageal impedance $\mathrm{pH}$ testing depending on the availability. The indication for esophageal function testing was initially established by the otolaryngologists in laryngeal disease based on objective laryngoscopy findings, such as posterior laryngitis, Reinke's edema, vocal cord dysfunction and pachydermia. On the other hand, the correlation between GER and tracheal stenosis was established based upon the prevalence of GER in this patient population. In our cohort of 175 patients with tracheal stenosis, $42 \%$ tested positive for pathologic GER on esophageal $\mathrm{pH}$ study (31) that is similar to another series (10). Clinically, we have employed the following criteria to perform esophageal function testing in patients with tracheal stenosis:

* Presence of Cotton-Myer grade 4 ("blind end") tracheal stenosis (Figure 5);

* Late recurrence of the stenosis after tracheal resection ( $>5$ years); 
* Persistent mucosal inflammation at the stenosis site;

* Subglottic or laryngotracheal stenosis refractory to dilatation, requiring 3 or more dilatation sessions.

We use the dual-probe esophageal $\mathrm{pH}$ testing that enables concomitant $\mathrm{pH}$ measurements between the lower and upper esophagus. The standard distance between probes in commercial catheters varies from 15 to $18 \mathrm{~cm}$. The

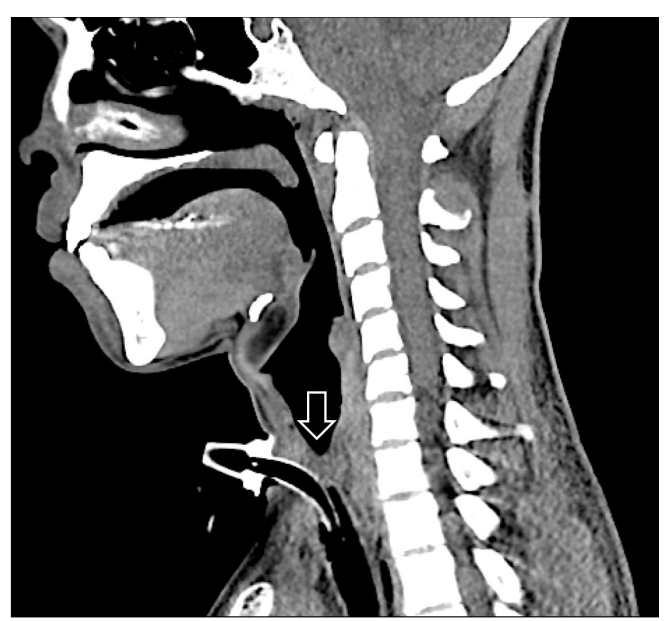

Figure 5 Sagittal reconstruction of CT scan in a patient with GER and a Cotton-Myer grade 4 tracheal stenosis (arrow showing the "blind-end" stenosis). standard DeMeester scoring system uses normal $\mathrm{pH}$ values according to Jamieson et al. (53) based on the measurements obtained in the distal esophageal probe (Figure 6). For the proximal probe we consider the detection of any reflux episode $(\mathrm{pH}<4)$ as an abnormal finding. The esophageal manometry is performed routinely before the $\mathrm{pH}$ study in order to assess esophageal motility and to ascertain an accurate positioning of the distal $\mathrm{pH}$ probe $5 \mathrm{~cm}$ above the upper end of the lower esophageal sphincter.

The findings in the esophageal motility and in the $\mathrm{pH}$ study of patients with tracheal stenosis follow the same pattern found in other respiratory manifestations of GER are somewhat different. As opposed to GERD, patients with tracheal stenosis present a lesser percentage of motility disorders (37\% in our cohort) and the hypotonic lower esophageal sphincter remains the dominant feature (Table 1). Another interesting finding is the high incidence of abnormal $\mathrm{pH}$ studies (42\% in our cohort) with a prevalence of supine and supraesophageal reflux (31) (Table 2) which has also been described in the past (26).

Despite the incidence of abnormal esophageal $\mathrm{pH}$ studies in our cohort, the upper gastrointestinal endoscopy had abnormal findings in only 18\% (31). On the other hand, airway endoscopy often detects several abnormalities at the stenosis site, such as inflammation with friable mucosa and blind end stenosis (Figure 7). Nevertheless, patients

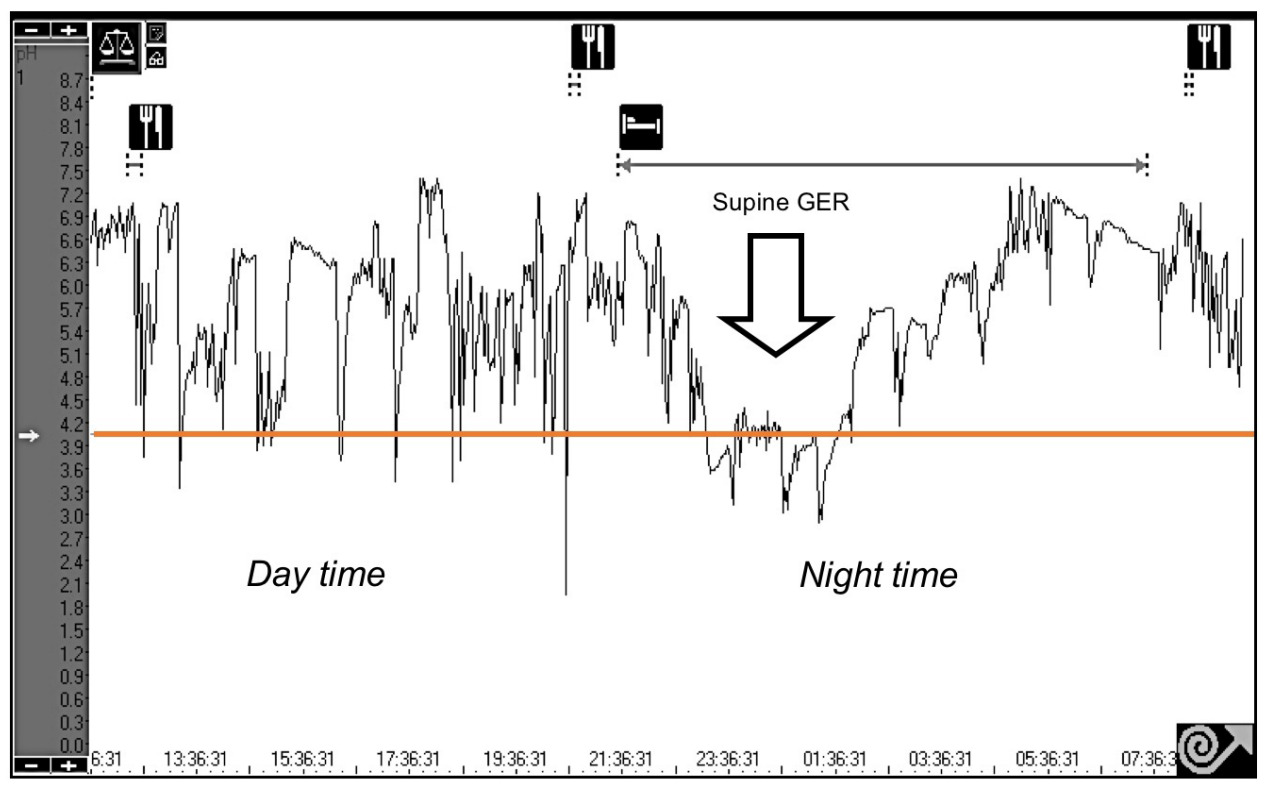

Figure 6 Esophageal pH study tracing in a patient with tracheal stenosis showing a predominance of supine gastroesophageal reflux (GER) (arrow). 
Table 1 Results of esophageal manometry in all patients

\begin{tabular}{|c|c|c|}
\hline Esophageal manometry $(n=169)$ & Measurements & Normal values* \\
\hline Average lower esophageal sphincter resting pressure $(\mathrm{mmHg})$ & $20.0 \pm 9.4$ & $14-34$ \\
\hline Maximum expiratory lower esophageal sphincter pressure $(\mathrm{mmHg})$ & $13.7 \pm 7.9$ & $10-35$ \\
\hline Distal esophageal pressure $(\mathrm{mmHg})$ & $99.2 \pm 35.9$ & $64-154$ \\
\hline
\end{tabular}

All values expressed as mean \pm standard deviation. ${ }^{*}$, normal values for esophageal motility according to the Esophageal Motility Laboratory, Hospital das Clinicas-HCFMUSP). Modified from Bianchi et al. (31).

Table 2 Results of ambulatory esophageal $\mathrm{pH}$ results in all patients

\begin{tabular}{lcc}
\hline 24-hour esophageal pH study $(n=175)$ & Measurements & $\begin{array}{c}\text { Normal } \\
\text { values* }\end{array}$ \\
\hline $\begin{array}{l}\text { Total number of distal esophageal } \\
\text { reflux episodes }\end{array}$ & $34.1 \pm 26.7$ & $<50$ \\
Total time with $\mathrm{pH}<4(\%)$ & $4.7 \pm 5.2$ & $<4.5$ \\
Time orthostatic with $\mathrm{pH}<4(\%)$ & $5.1 \pm 6.2$ & $<8.4$ \\
Time supine with $\mathrm{pH}<4(\%)$ & $3.6 \pm 6.2$ & $<3.5$ \\
DeMeester score & $19.7 \pm 20$ & $<14.7$ \\
$\begin{array}{l}\text { Total number of supraesophageal } \\
\text { reflux episodes }\end{array}$ & $1.1 \pm 2.3$ & 0 \\
\hline
\end{tabular}

All values expressed as mean \pm standard deviation. * , normal $\mathrm{pH}$ values according to Jamieson et al. (53).

with abnormal GER who are considered for fundoplication should undergo an upper gastrointestinal contrast study and endoscopy routinely.

\section{Treatment strategy and outcome of patients with tracheal stenosis and GER}

Patients presenting with the association tracheal stenosis and GER require a different management strategy. After the usual work up for the tracheal stenosis that includes CT scan of the neck/chest, airway endoscopy followed by the detection of GER using esophageal function testing, the patient is placed on proton pump inhibitors (e.g., omeprazole $80 \mathrm{mg}$ bid). Patients with tracheal stenosis are considered for either a laparoscopic modified Nissen fundoplication or continued medical treatment with high dose proton pump inhibitors (e.g., $40 \mathrm{mg}$ omeprazole bid) according to the following criteria:

* Fundoplication: presence of reflux-related

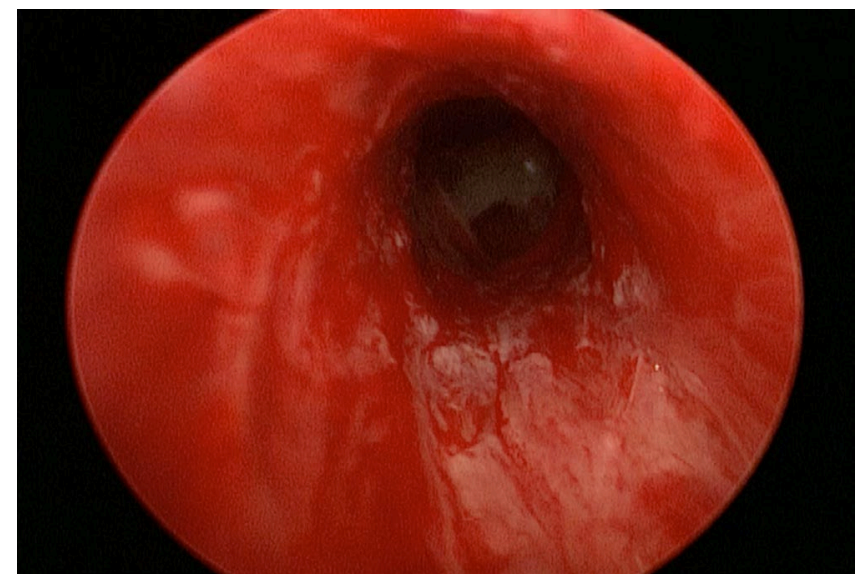

Figure 7 Persistent mucosal inflammation at the stenosis site detected during tracheoscopy in a patient with GER (DeMeester score of 38 , predominant supine reflux and concomitant supraesophageal reflux).

complications such as erosive esophagitis, esophageal stenosis; Barrett's; DeMeester score $\geq 30$; absence of severe comorbidities (type 1 diabetes, cardiovascular condition, renal failure, asthma, or chronic obstructive pulmonary disease); body mass index below $30 \mathrm{~kg} / \mathrm{m}^{2}$; persistent mucosal inflammation at the tracheal stenosis site after 3 to 6 months of high dose proton pump inhibitors.

* Proton pump inhibitors: patients with pathologic GER as detected by 24-hour ambulatory esophageal $\mathrm{pH}$ study who did not fulfill the criteria for fundoplication, regardless of the presence of typical upper gastrointestinal symptoms; patients with restricted mobility (bedridden or wheelchair bound).

The decision-making process went through multidisciplinary rounds for either laparoscopic modified 

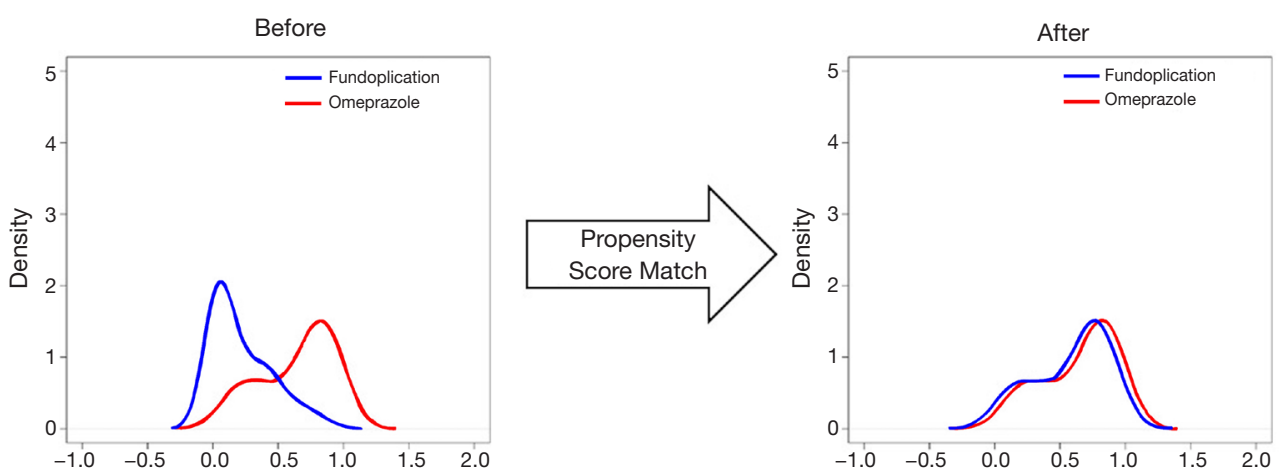

\begin{tabular}{|c|c|c|c|c|}
\hline & Odds Ratio & Standard Error & $95 \%$ Confidence Interval & $\mathrm{P}$ \\
\hline Intercept & - & 0.52 & - & 0.31 \\
\hline Fundoplication & 5.31 & 0.79 & $2.41-11.7$ & 0.03 \\
\hline Hypotonic LES & 0.44 & 0.82 & $0.19-0.99$ & 0.31 \\
\hline
\end{tabular}

Figure 8 Density graphs before and after propensity score matching. The odds ratio showing that patients with tracheal stenosis submitted to fundoplication had a better chance of resolution of the tracheal stenosis compared to patients treated medically with omeprazole (40 mg bid). Modified from Bianchi et al. (31) by permission.

Nissen fundoplication or medical treatment. This required a close interaction between a team composed by the thoracic surgeon, gastroenterologist and esophageal surgeon.

Six months after laparoscopic modified Nissen fundoplication a repeat esophageal motility and dual-probe 24-hour $\mathrm{pH}$ study is performed in order to ascertain that the reflux control has been achieved. We tend to consider as an ideal control of GER when a dramatic reduction of reflux episodes and normal DeMeester Score are obtained (Table 3).

The outcome of tracheal stenosis following detection and treatment of reflux was published recently by our group according to the strategy described above (31). Using propensity score matching, a comparison was performed between patients with tracheal stenosis presenting pathological GER on the 24-hour ambulatory esophageal pH study. Patients with pathological GER underwent fundoplication or medical treatment with omeprazole $(80$ $\mathrm{mg}$ bid), and patients with normal $\mathrm{pH}$ study were followed. After a 2-year follow-up the outcomes of tracheal stenosis were considered as: Favorable (stability of the stenosis was achieved, not requiring further dilatation and allowing for definitive decannulation or tracheal resection); Unfavorable (none of the previous outcomes were achieved). The results demonstrated that fundoplication yielded to a favorable outcome of the tracheal stenosis compared to omeprazole (odds ratio 5.31; confidence interval 2.41-11.7; $\mathrm{P}=0.03$ ) (Figure 8 ), and the outcome was similar compared to the patients without pathological GER (odds ratio 1; confidence interval 0.47-2.11; $\mathrm{P}=0.99$ ). On the other hand, the comparison between patients treated with omeprazole versus those without pathological reflux showed that patients without GER had tripled the chance of a favorable outcome of the tracheal stenosis compared to those treated with omeprazole (odds ratio 3.54; confidence interval 2.026.19; $\mathrm{P}=0.02)$.

Our study was the first to demonstrate using propensity score matching that patients submitted to laparoscopic fundoplication for the control of GER had quintupled the chance of a favorable outcome of the tracheal stenosis compared to those patients receiving high dose omeprazole, and had an equal chance of a favorable outcome compared to patients without pathological reflux. The lesser favorable outcome of the tracheal stenosis obtained in patients with pathologic GER treated with high dose omeprazole. This finding reinforces the hypothesis that the control of the acid output alone is not enough, and other contents of the refluxate such as enzymes may be also involved in the process (31). The results of the study led us to assess and treat GER in selected patients with refractory or complex 
Table 3 Results of ambulatory esophageal $\mathrm{pH}$ study in a patient cohort with tracheal stenosis before and 6 months after laparoscopic modified Nissen fundoplication

\begin{tabular}{lccc}
\hline Parameter & $\begin{array}{c}\text { Before } \\
\text { fundoplication } \\
(\mathrm{N}=20)\end{array}$ & $\begin{array}{c}\text { After } \\
\text { fundoplication } \\
(\mathrm{N}=19)\end{array}$ & $\begin{array}{l}\text { Normal } \\
\text { values }\end{array}$ \\
\hline $\begin{array}{l}\text { Total number of distal } \\
\text { esophageal reflux } \\
\text { episodes }(\mathrm{pH}<4)\end{array}$ & $68.8 \pm 21.7$ & $4.6 \pm 10.2$ & $<50$ \\
\% total time $(\mathrm{pH}<4)$ & $12.1 \pm 5.2$ & $2.0 \pm 3.5$ & $<4.5$ \\
$\%$ time orthostatic $(\mathrm{pH}<4)$ & $12.5 \pm 8.9$ & $1.2 \pm 3.4$ & $<8.4$ \\
\% time supine $(\mathrm{pH}<4)$ & $11 \pm 9.3$ & $2.0 \pm 5.7$ & $<3.5$ \\
$\begin{array}{l}\text { DeMeester score } \\
\text { Number of patients with }\end{array}$ & $97.7 \pm 17.7$ & $6.8 \pm 13.1$ & $<14.7$ \\
$\begin{array}{l}\text { supraesophageal acid } \\
\text { reflux }\end{array}$ & $9(45 \%)$ & 0 & 0 \\
$\begin{array}{l}\text { Supraesophageal acid } \\
\text { reflux episodes per patient }\end{array}$ & 1.7 & & \\
\hline
\end{tabular}

Values expressed as mean \pm standard deviation or absolute value and percentage. ${ }^{*}$, normal $\mathrm{pH}$ values according to Jamieson et al. (53).

benign post-intubation tracheal stenosis.

\section{Summary}

There are many factors contributing to the onset, severity and persistence of benign tracheal stenosis. There is evidence that GER plays a local role enhancing the collagen proliferation and affecting the local microbiome among other factors. The detection and assessment of GER must be carried out using objective methods such as 24hour ambulatory esophageal $\mathrm{pH}$ study or impedance $\mathrm{pH}$ study in addition to motility, radiographic and esophageal endoscopy since the usual clinical signs and symptoms are often absent in many patients with tracheal stenosis. The 24-hour ambulatory esophageal $\mathrm{pH}$ study provides quantitative results based upon numerical data that can be used to ascertain either the presence and severity of GER or its control after treatment. The tendency of detecting and treating GER in such patients based on the premises used for GERD can be misleading because the clinical behavior of GER on patients with tracheal stenosis seems to be different from what is found in patients with GERD. Therefore, one must consider GER in tracheal stenosis as a different entity that requires further studies in order to clarify its mechanisms and effects. For the time being, the surgical control of GER in selected patients with tracheal stenosis is reasonable and echoes what has been suggested for other respiratory manifestations of GER. Our recent study corroborates the idea that testing for reflux should be used more liberal in patients with tracheal stenosis, and surgical treatment of GER by fundoplication is related to a better outcome of the stenosis rather than medical therapy with proton pump inhibitors.

\section{Acknowledgments}

Funding: None.

\section{Footnote}

Provenance and Peer Review: This article was commissioned by the editorial office, Translational Cancer Research for the series "Recent Developments in Benign Tracheal Stenosis". The article has undergone external peer review.

Conflicts of Interest: All authors have completed the ICMJE uniform disclosure form (available at http:// dx.doi.org/10.21037/tcr.2020.03.24). The series "Recent Developments in Benign Tracheal Stenosis" was commissioned by the editorial office without any funding or sponsorship. BJB and PFGC served as the unpaid Guest Editors of the series. The authors have no other conflicts of interest to declare.

Ethical Statement: The authors are accountable for all aspects of the work in ensuring that questions related to the accuracy or integrity of any part of the work are appropriately investigated and resolved.

Open Access Statement: This is an Open Access article distributed in accordance with the Creative Commons Attribution-NonCommercial-NoDerivs 4.0 International License (CC BY-NC-ND 4.0), which permits the noncommercial replication and distribution of the article with the strict proviso that no changes or edits are made and the original work is properly cited (including links to both the formal publication through the relevant DOI and the license). See: https://creativecommons.org/licenses/by-nc-nd/4.0/.

\section{References}

1. Sarper A, Ayten A, Eser I, et al. Tracheal stenosis after 
tracheostomy or intubation: review with special regard to cause and management. Tex Heart Inst J 2005;32:154-8.

2. Grillo HC, Donahue DM, Mathisen DJ, et al. Postintubation tracheal stenosis. Treatment and results. J Thorac Cardiovasc Surg. 1995;109:486-92; discussion 492-3.

3. Pearson FG, Andrews MJ. Detection and management of tracheal stenosis following cuffed tube tracheostomy. Ann Thorac Surg 1971;12:359-74.

4. Stauffer JL, Olson DE, Petty TL. Complications and consequences of endotracheal intubation and tracheotomy. A prospective study of 150 critically ill adult patients. Am J Med 1981;70:65-76.

5. Grillo HC, Mathisen DJ, Wain JC. Laryngotracheal resection and reconstruction for subglottic stenosis. Ann Thorac Surg 1992;53:54-63.

6. Mims JW. The impact of extra-esophageal reflux upon diseases of the upper respiratory tract. Curr Opin Otolaryngol Head Neck Surg 2008;16:242-6.

7. Maher MM, Darwish AA. Study of respiratory disorders in endoscopically negative and positive gastroesophageal reflux disease. Saudi J Gastroenterol 2010;16:84-9.

8. Moraes-Filho JP, Chinzon D, Eisig JN, et al. Prevalence of heartburn and gastroesophageal reflux disease in the urban Brazilian population. Arq Gastroenterol 2005;42:122-7.

9. Locke GR 3rd, Talley NJ, Fett SL, et al. Prevalence and clinical spectrum of gastroesophageal reflux: a population-based study in Olmsted County, Minnesota. Gastroenterology 1997;112:1448-56.

10. Munir RA, Ehtisham M, Klopper E, et al. Correlation between tracheal stenosis and gastroesphageal reflux disease. Am J Respir Crit Care Med 2015;191:A3075.

11. Vakil N, van Zanten SV, Kahrilas P, et al. The Montreal definition and classification of gastroesophageal reflux disease: a global evidence-based consensus. Am J Gastroenterol. 2006;101:1900-20; quiz 1943.

12. dos Santos LH, Ribeiro IO, Sánchez PG, et al. Evaluation of pantoprazol treatment response of patients with asthma and gastroesophageal reflux: a randomized prospective double-blind placebo-controlled study. J Bras Pneumol 2007;33:119-27.

13. Machado MM, Cardoso PF, Ribeiro IO, et al. Esophageal manometry and 24-h esophageal pH-metry in a large sample of patients with respiratory symptoms. J Bras Pneumol 2008;34:1040-8.

14. Bandeira CD, Rubin AS, Cardoso PF, et al. Prevalence of gastroesophageal reflux disease in patients with idiopathic pulmonary fibrosis. J Bras Pneumol 2009;35:1182-9.
15. D'Ovidio F, Keshavjee S. Gastroesophageal reflux and lung transplantation. Dis Esophagus 2006;19:315-20.

16. Fortunato GA, Machado MM, Andrade CF, et al. Prevalence of gastroesophageal reflux in lung transplant candidates with advanced lung disease. J Bras Pneumol 2008;34:772-8.

17. Posner S, Zheng J, Wood RK, et al. Gastroesophageal reflux symptoms are not sufficient to guide esophageal function testing in lung transplant candidates. Dis Esophagus 2018. doi: 10.1093/dote/dox157.

18. Ratier JC, Pizzichini E, Pizzichini M. Gastroesophageal reflux disease and airway hyperresponsiveness: concomitance beyond the realm of chance? J Bras Pneumol 2011;37:680-8.

19. Shaker R, Milbrath M, Ren J, et al. Esophagopharyngeal distribution of refluxed gastric acid in patients with reflux laryngitis. Gastroenterology 1995;109:1575-82.

20. Koufman JA. The otolaryngologic manifestations of gastroesophageal reflux disease (GERD): a clinical investigation of 225 patients using ambulatory 24-hour $\mathrm{pH}$ monitoring and an experimental investigation of the role of acid and pepsin in the development of laryngeal injury. Laryngoscope 1991;101:1-78.

21. Ylitalo R, Ramel S. Extraesophageal reflux in patients with contact granuloma: a prospective controlled study. Ann Otol Rhinol Laryngol 2002;111:441-6.

22. Brandenburg JH. Idiopathic subglottic stenosis. Trans Am Acad Ophthalmol Otolaryngol 1972;76:1402-6.

23. Terra RM, de Medeiros IL, Minamoto H, et al. Idiopathic tracheal stenosis: successful outcome with antigastroesophageal reflux disease therapy. Ann Thorac Surg 2008;85:1438-9.

24. Bain WM, Harrington JW, Thomas LE, et al. Head and neck manifestations of gastroesophageal reflux. Laryngoscope 1983;93:175-9.

25. Little FB, Koufman JA, Kohut RI, et al. Effect of gastric acid on the pathogenesis of subglottic stenosis. Ann Otol Rhinol Laryngol 1985;94:516-9.

26. Toohill RJ, Ulualp SO, Shaker R. Evaluation of gastroesophageal reflux in patients with laryngotracheal stenosis. Ann Otol Rhinol Laryngol 1998;107:1010-4.

27. Blumin JH, Johnston N. Evidence of extraesophageal reflux in idiopathic subglottic stenosis. Laryngoscope 2011;121:1266-73.

28. Wang J, Zhao Y, Ren J, et al. Pepsin in saliva as a diagnostic biomarker in laryngopharyngeal reflux: a metaanalysis. Eur Arch Otorhinolaryngol 2018;275:671-8.

29. Walner DL, Stern Y, Gerber ME, et al. Gastroesophageal 
reflux in patients with subglottic stenosis. Arch Otolaryngol Head Neck Surg 1998;124:551-5.

30. Maronian NC, Azadeh H, Waugh P, et al. Association of laryngopharyngeal reflux disease and subglottic stenosis. Ann Otol Rhinol Laryngol 2001;110:606-12.

31. Bianchi ET, Cardoso PFG, Minamoto H, et al. The Impact Of Fundoplication For The Treatment Of GastroEsophageal Reflux In The Outcome Of Benign Tracheal Stenosis. J Thorac Cardiovasc Surg 2019;158:1698-706.

32. Kocdor P, Siegel ER, Suen JY, et al. Comorbidities and factors associated with endoscopic surgical outcomes in adult laryngotracheal stenosis. Eur Arch Otorhinolaryngol 2016;273:419-24.

33. Tawfik KO, Houlton JJ, Compton W, et al. Laryngotracheal reconstruction: a ten-year review of risk factors for decannulation failure. Laryngoscope 2015;125:674-9.

34. Cheng T, Carpenter D, Cohen S, et al. Investigating the effects of laryngotracheal stenosis on upper airway aerodynamics. Laryngoscope 2018;128:E141-9.

35. Wang W, Tovar JA, Eizaguirre I, et al. Airway obstruction and gastroesophageal reflux: an experimental study on the pathogenesis of this association. J Pediatr Surg 1993;28:995-8.

36. Boesch RP, Shah P, Vaynblat M, et al. Relationship between upper airway obstruction and gastroesophageal reflux in a dog model. J Invest Surg 2005;18:241-5.

37. Bhatia R, Pagala $M$, Vaynblat $M$, et al. Intrathoracic airway obstruction and gastroesophageal reflux: a canine model. Pediatr Pulmonol 2012;47:1097-102.

38. Masuda T, Mittal SK, Kovacs B, et al. Thoracoabdominal pressure gradient and gastroesophageal reflux: insights from lung transplant candidates. Dis Esophagus 2018. doi:10.1093/dote/doy025

39. Carpagnano GE, Resta O, Ventura MT, et al. Airway inflammation in subjects with gastro-oesophageal reflux and gastro-oesophageal reflux-related asthma. J Intern Med 2006;259:323-31.

40. Duynstee ML, de Krijger RR, Monnier P, et al. Subglottic stenosis after endolaryngeal intubation in infants and children: result of wound healing processes. Int J Pediatr Otorhinolaryngol. 2002;62:1-9.

41. Dillard DG, Gal AA, Roman-Rodriguez J, et al. Transforming growth factor and neutralizing antibodies in subglottic stenosis. Ann Otol Rhinol Laryngol 2001;110:393-400.

42. Jarmuz T, Roser S, Rivera H, et al. Transforming growth factor-beta1, myofibroblasts, and tissue remodeling in the pathogenesis of tracheal injury: potential role of gastroesophageal reflux. Ann Otol Rhinol Laryngol 2004;113:488-97.

43. Aldhahrani A, Powell J, Ladak S, et al. The Potential Role of Bile Acids in Acquired Laryngotracheal Stenosis. Laryngoscope 2018;128:2029-33.

44. Biscetti F, Flex A, Alivernini S, et al. The Role of High-Mobility Group Box-1 and Its Crosstalk with Microbiome in Rheumatoid Arthritis. Mediators Inflamm 2017;2017:5230374.

45. Ahmed U, Tanwir F. Association of periodontal pathogenesis and cardiovascular diseases: a literature review. Oral Health Prev Dent 2015;13:21-7.

46. Tapashetti RP, Guvva S, Patil SR, et al. C-reactive Protein as Predict of Increased Carotid Intima Media Thickness in Patients with Chronic Periodontitis. J Int Oral Health 2014;6:47-52.

47. Pérez-Losada M, Graham RJ, Coquillette M, et al. The temporal dynamics of the tracheal microbiome in tracheostomised patients with and without lower respiratory infections. PloS One 2017;12:e0182520.

48. Costerton JW, Montanaro L, Arciola CR. Biofilm in implant infections: its production and regulation. Int J Artif Organs 2005;28:1062-8.

49. Nouraei SA, Petrou MA, Randhawa PS, et al. Bacterial colonization of airway stents: a promoter of granulation tissue formation following laryngotracheal reconstruction. Arch Otolaryngol Head Neck Surg 2006;132:1086-90.

50. Bibas BJ, Terra RM, Oliveira Junior AL, et al. Predictors for postoperative complications after tracheal resection. Ann Thorac Surg 2014;98:277-82.

51. Zhang Y, Wang X, Li HX, et al. Human oral microbiota and its modulation for oral health. Biomed Pharmacother 2018;99:883-93.

52. Ylitalo R, Ramel S, Hammarlund B, et al. Prevalence of extraesophageal reflux in patients with symptoms of gastroesophageal reflux. Otolaryngol Head Neck Surg 2004;131:29-33.

53. Jamieson JR, Stein HJ, DeMeester TR, et al. Ambulatory 24-h esophageal $\mathrm{pH}$ monitoring: normal values, optimal thresholds, specificity, sensitivity, and reproducibility. Am J Gastroenterol 1992;87:1102-11.

Cite this article as: Cardoso PFG, Minamoto H, Bibas BJ, Pego-Fernandes PM. Impact of gastroesophageal reflux in the pathogenesis of tracheal stenosis. Transl Cancer Res 2020;9(3):2123-2135. doi: 10.21037/tcr.2020.03.24 